\title{
Imaginatrix: \\ School of Cyber Wizardry
}

\author{
Batuhan Bintas \\ Artist, Visionary, Educator \\ Author, Founder of Imaginatrix \\ London, United Kingdom \\ inspire@cyberrabbit.co.uk
}

\section{INTRODUCTION}

With the advancement in digital technology, new ways of expressing ourselves, experiencing realities, governance models and value systems are merging. In other words; in front of our eyes we are witnessing the establishment of a new civilization.

It is important to educate ourselves, especially the upcoming generations about these new ways of living (figure 1)

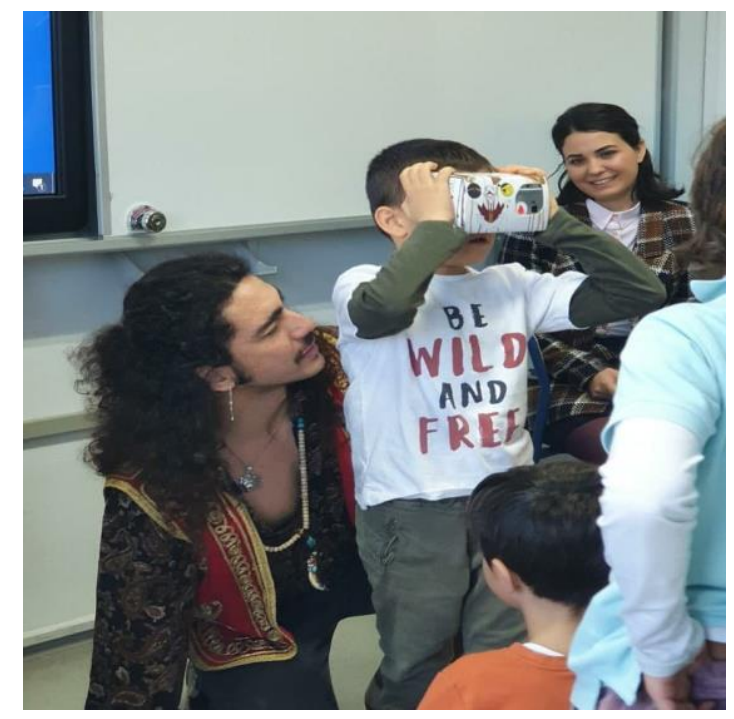

Figure 1: Batuhan showing VR to students.

School of Cyber Wizardry's vision is to live in a harmonious society that uses technology responsibly to ignite the imagination. Our mission is to provide tools and education that empowers imagination through cyberspace.

\section{EDUCATION}

Imaginatrix education model has two main classes;

- Theory of Knowledge

- Cyber Magician

Theory of Knowledge classes are purely theoretical whereas Cyber Magician Classes will educate practically. Theory of Knowledge classes continue throughout the whole education programme and will be updated with any new development related to each subject.

Cyber Magician classes are specialisations of each skill. In the foundation year of this programme the course will be holding all Cyber Magician Classes. In year one students will be able to choose from four Cyber Magician Classes they want to specialise in, recommended will be one to two.

\subsection{Theory of Knowledge}

These classes are designed for all students:

\subsubsection{Theory of Digital World}

- Blockchain

- Artificial Intelligence (Al)

- Extended Reality (XR, AR, MR, VR)

- Cryptocurrency

- Internet

- Decentralisation

- Decentralised Autonomous Organisation(DAO)

- Music, Art, Fashion

2.1.2 Theory of Magic

- Alchemy

$$
\circ \text { Hermetic Teachings }
$$

- Mythical Imagination

- History of magic

- Ancient civilizations, Mythology 


\subsection{Cyber Magician Classes}

There are 4 major Cyber Magician classes.

\subsubsection{Portalmancers}

Portal openers between the imagined and physical reality - Creating worlds in Cyber Space.

In this class students learn XR technologies (figure 2):

- Unity / Unreal Engine

- Programming / Coding

$\begin{array}{ll}\circ & \text { Mobile (APP) } \\ \circ & \text { Computer } \\ \circ & \text { WebGL }\end{array}$

\subsubsection{Beastiaries}

Summoners of imagined characters.

In this class students learn about character design and animation:

- 2D: TV Paint, Photoshop, Procreate

- 3D: Maya, Blender, ZBrush

- VR: Tilt Brush, Masterpiece VR

- Unity Animation

\subsubsection{Sonics}

Masters of the sound - From frequencies to immersive production:

In this class students learn about sound engineering:

- Synthesizers

- Ableton

- DJing

- Binaural beats

\subsubsection{Fashionetics}

Designers of the future's style - Merging robotics with fashion.

In this class students learn about:

- Haptics

- Holographic clothes

- Digitally augmented fashion

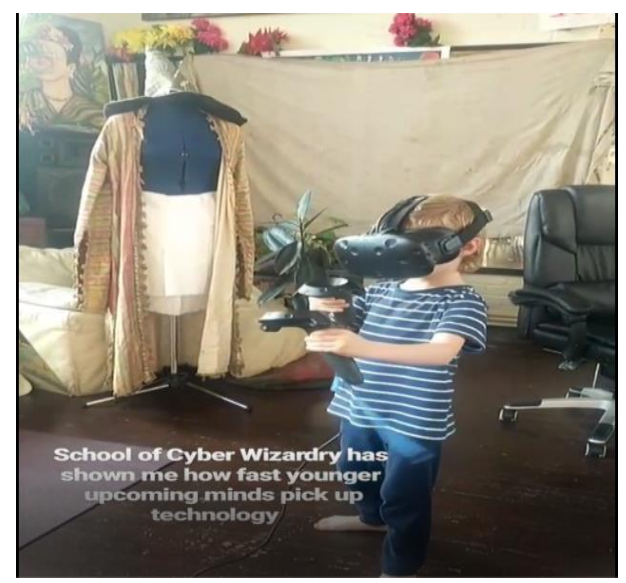

\section{GUILDS}

Guilds are the Decetralised Autonomous Organisations (DAOs) of the school. Students from different Cyber Magician classes come vision.

Each guild will have a:

- voting system

- value system

- project system

Guild infrastructures will be enabled by Magix coin.

\section{MAGIX}

The cryptocurrency system of the school. Each student starts with a certain amount and they can increase them by contributing towards their DAOs, by sharing their skills and selling products they build. Internally these tokens can be used within school and each DAO. Externally, there will be a specialised marketplace where both students and people from outside the school will be able to purchase headsets, robes, hire skills and even buy virtual land in Cyberland. Eventually the coins will be tradable on the cryptocurrency exchange markets.

\section{NFT ART MARKET PLACE FOR KIDS}

Imaginatrix will have a NFT Art market available for the students of School of Cyber Wizardry as well as kids of all ages outside the education programme. Magix will be the currency of the market.

\section{CYBERLAND}

A decentralized digital education platform. Imaginatrix will have its own digital platform for education. This world can be accessed through XR technologies as well as WEBGL.

Digital teachings will take place here. Cyberland will be open for other education institutions as well. They will be able to purchase land with Magix coins, build their education system and monetize it.

\section{ROADMAP}

We are officially running pilot practical XR classes at the Edinburgh Primary School in London as well as theory classes over online Zoom meetings. The programme will expand as more schools are now interested in joining. We are teaching both at schools and at our own premises.

Figure 2: A young student learning XR. 